\title{
Influência da Seleção sobre a Qualidade da Dieta Ingerida por Caprinos com Feno Oferecido em Excesso ${ }^{1}$
}

\author{
José Humberto Vilar da Silva², Marcelo Teixeira Rodrigues ${ }^{3}$, Joaquim Campos ${ }^{3}$
}

\begin{abstract}
RESUMO - O objetivo deste trabalho foi avaliar o hábito alimentar, consumo de matéria seca e desempenho em cabras alimentadas com fenos de rami (Boehemeria nivea G.), soja (Neonotonia wightii (L.) M.) e capim-elefante napier (Pennisetum purpureum Sch.), oferecidos para permitir excesso de $30 \mathrm{ou} 60 \%$, acima do consumo medido do dia anterior. Trinta e seis cabras foram distribuídas em delineamentointeiramente ao acaso com seis tratamentos em arranjo fatorial de $3 \times 2$ (fenos e níveis de oferta). O tamanho médio de partícula dos fenos foi mantido constante em $0,4 \mathrm{~cm}$. Os consumos de matéria seca e proteína bruta aumentaram quando o feno de rami foi oferecido com excesso de $60 \%$, comparado a $30 \%$. Houve redução no consumo de lignina quando o feno de soja foi oferecido no nível de $60 \%$. Inversamente, decréscimo no consumo de proteína bruta e aumento no de fibra em detergente ácido e lignina foram observados, quando a oferta do feno de capim-elefante napier variou de 30 a $60 \%$. Maior ganho em peso médio diário foi observado para os animais que consumiram o feno de rami. Estes resultados sugeriram que o feno de rami foi o mais indicado para uso em manejo de alimentação de cabras, com fenos oferecidos em excesso.
\end{abstract}

Palavras-chave: capim-elefante napier, feno, rami, seleção alimentar, soja

\section{Influence of Selection on the Quality of the Ingested Diet by Goats with Hays Offered in Excess}

ABSTRACT - The objective of this work was to evaluate the feeding behavior, dry matter intake, and performance in goats fed hays of ramie (Boehemeria nivea G.), soybean (Neonotonia wightii) and elephant grass (Pennisetum purpureum Schum., cv. napier), offered to allow an excess of 30 or $60 \%$, above the intake measured in the previous day. Thirty-six goats were allotted to a completely randomized design with six treatments in a factorial arrangement of $3 \times 2$ (hay and level of offer). The mean particle size of the hays was kept constant in $0.4 \mathrm{~cm}$. The dry matter and crude protein intake increased as ramie hay was fed at $60 \%$ excess as compared to $30 \%$. A reduction in the lignin intake occurred when the soybean hay was fed at the $60 \%$ level. Conversely, a decrease in crude protein intake and an increase in fiber detergent acid and lignin were observed as the offer of elephant cv. napier grass varied from 30 to $60 \%$. Higher daily weight gain was observed for animals fed ramie hay. These results suggested that ramie hay was the best indication for the use in the feeding management of goats, with hays offered in excess.

Key Words: elephant grass cv. Napier, hay, ramie, feed selection, soybean

\section{Introdução}

Várias técnicas têm sido empregadas no conhecimento das preferências do animal por alguns alimentos, ou partes deles, em nível de campo. Os avanços já alcançados têm permitido a adaptação vantajosa desses conhecimentos às condições controladas de ambientes fechados.

A exploração econômica do hábito seletivo de caprinos em confinamento visa substituir parte do concentrado pelo desenvolvimento de condições, para que os animais selecionem as frações mais ricas dos alimentos volumosos.

Sabe-se que o excesso de oferta de forragens no cocho estimula o consumo (MORAND-FEHR, 1981; OWEN et al., 1987) e o desempenho dos caprinos, em comparação àqueles mantidos sob restrição de oferta, principalmente quando são utilizadas forrageiras maduras (BROWN e WEIR, 1987). Isso é possível graças à capacidade dos caprinos de escolher, mesmo em condições de confinamento, as porções mais apetecíveis do alimento oferecido em excesso (JOHNSON e VAN EYS, 1987).

Entretanto, a alimentação de cabras com excesso de alimentos no cocho, objetivando estimular o processo seletivo de animais confinados, exige cuidados especiais, pois, se o produtor permitir sobra muito grande, pode estar utilizando mal os recursos forrageiros disponíveis. Portanto, torna-se necessário desenvolver estratégia própria de acordo com a quantidade e o tipo de alimento disponível (MORAND-FEHR, 1981).

\footnotetext{
1 Parte da tese de Mestrado apresentada à UFV pelo primeiro autor, bolsista do CNPq.

2 Colégio Agrícola André Vidal de Negreiros/DAP/CFT/UFPB - CEP 58.220-000/Bananeiras - PB.

3 Professor DZO/UFV - CEP 36.570-000/Viçosa - MG
} 
O rami (Boehemeria nivea G.), a planta de soja perene (Neonotonia wightii) e o capim-elefante napier (Pennisetum purpureum Sch.) já são comuns na alimentação de caprinos. Entretanto, informações sobre o valor dessas espécies forrageiras e seu uso adequado, objetivando acentuar o grau de seletividade e, conseqüientemente, o desempenho dos animais, não são encontradas na literatura.

O objetivo deste experimento foi estudar as relações do tamanho da oferta de três fenos, picados em tamanho de partícula médio de $0,4 \mathrm{~cm}$, com a qualidade do material ingerido, o consumo e ganho em peso de cabras, em condições de confinamento.

\section{Material e Métodos}

O trabalho foi conduzido na Seção de Caprinocultura do Departamento de Zootecnia da UFV. Foram usados 36 caprinos em fase de crescimento, peso médio de $27,5 \pm 4,2 \mathrm{~kg}$, mestiços da Raça Alpina x Sem Raça Definida (SRD) e alojados em gaiolas individuais de $1,2 \mathrm{~m}^{2}$.

Preparo dos fenos e da mistura concentrada

A parte aérea das plantas de rami e soja colhidas aos 60 dias e do capim-elefante var. napier colhido aos 120 dias do corte de uniformização foi picada para tamanho médio de partícula de $0,4 \mathrm{~cm}$ e seca artificialmente, em secador de grãos de cereais, até atingir cerca de $10 \%$ de umidade. A temperatura de secagem variou de 40 a $60^{\circ} \mathrm{C}$ e o tempo de exposição ao calor durou de 14 a 16 horas.

Como as diferenças no desempenho deveriam ser proporcionadas pela qualidade do material ingerido de cada feno, forneceu-se uma mistura concentra- da em quantidades suficientes para satisfazer às necessidades energético-protéicas de mantença de cabras mantidas em condições de mínima atividade (NATIONAL RESEARCH COUNCIL - NRC, 1981). O concentrado foi constituído de 93,8\% de milho desintegrado com palha e sabugo (MDPS), 5,4\% de farelo de soja e $0,7 \%$ de carbonato de cálcio. A composição química e a digestibilidade in vitro da matéria seca (DIVMS) dos fenos, das folhas e das hastes encontram-se na Tabela 1.

\section{Manejo alimentar e análises laboratoriais}

Os fenos foram distribuídos pela manhã, nos níveis de ofertas de 30 e $60 \%$, acima do consumo do dia anterior. A oferta do concentrado foi realizada em cochos separados do volumoso na parte da tarde. Os caprinos tiveram livre acesso à água e mistura mineral. A fase de adaptação correspondeu a 15 dias e o período de coletas, a 38 dias.

Adotou-se o delineamento inteiramente ao acaso, em esquema fatorial $3 \times 2$ (três fenos $\mathrm{x}$ dois níveis de ofertas), com seis repetições. Os pesos dos animais foram tomados a cada quinze dias, ajustando-se a quantidade de concentrado fornecido a cada animal, com base na variação dos pesos metabólicos $\left(\mathrm{kg} \mathrm{PV}^{0,75}\right)$. O conteúdo de proteína bruta foi determinado utilizando-se o processo semimicro Kjeldahl. Os conteúdos de FDN, FDA e lignina e a digestibilidade in vitro (DIVMS) foram obtidos pelas técnicas citadas por SILVA (1990). Na análise de DIVMS, o animal doador de líquido de rúmen foi alimentado com silagem de milho, fubá e farelo de soja. Os valores percentuais de proteína bruta $(\mathrm{PB})$, fibra em detergente neutro (FDN), fibra em detergente ácido (FDA) e lignina (LIG) das porções ingeridas foram estimados

Tabela 1 - Matéria seca (MS), proteína bruta (PB), fibra detergente neutro (FDN), fibra detergente ácido (FDA), lignina (LIG) e desaparecimento in vitro da matéria seca (DIVMS) de fenos, folhas e hastes

Table 1 - Dry matter (DM), crude protein (CP), neutral detergent fiber (NDF), acid detergent fiber (ADF), lignin (LIG) and in vitro dry matter disapperance (IDMD) of hays, leaves and stems

\begin{tabular}{lcccccc}
\hline \multirow{2}{*}{ Feno } & \multicolumn{7}{c}{$\% \mathrm{MS}(\% D M)$} \\
\cline { 2 - 7 } Hay & $\% \mathrm{MS}$ & $\mathrm{PB}$ & FDN & FDA & LIG & DIVMS \\
\hline Rami(ramie) & 88,40 & $16,15^{\mathrm{a}}$ & $60,05^{\mathrm{b}}$ & $48,20^{\mathrm{b}}$ & 12,43 & 48,83 \\
Folhas (leaves) & 88,56 & 21,23 & 39,61 & 34,46 & - & 59,06 \\
Hastes (stems) & 88,94 & 8,94 & 70,06 & 58,13 & - & - \\
Soja (soybean) & 89,11 & $12,53^{\mathrm{b}}$ & $64,85^{\mathrm{b}}$ & $46,54^{\mathrm{b}}$ & 9,06 & 56,19 \\
Folhas (leaves) & 87,51 & 20,77 & 51,65 & 29,91 & - & 63,51 \\
Hastes (stems) & 88,10 & $6,43^{2}$ & 72,00 & 61,27 & - & 43,53 \\
Napier (napier grass) & 90,94 & $4,52^{\mathrm{c}}$ & $83,03^{\mathrm{a}}$ & $52,41^{\mathrm{a}}$ & 8,05 & 43,96 \\
Folhas (leaves) & 90,34 & 5,64 & 79,82 & 50,32 & - & 52,14 \\
Colmos (stems) & 90,42 & 1,49 & 87,91 & 64,62 & - & 31,12 \\
\hline
\end{tabular}

a,b,c Médias, na coluna, seguidas de diferentes letras são diferentes pelo teste Tukey $(P<0,05)$.

$a, b, c$ Means, within a colunm, followed by different letters are diferent by test Tukey $(P<.05)$. 
Rev. bras. zootec.

pela diferença entre a quantidade do nutriente fornecido e rejeitado, divididos pela matéria seca ingerida.

\section{Delineamento experimental}

As análises estatísticas foram realizadas pelo programa SAEG (UFV, 1982). O modelo estatístico utilizado nas análises dos dados foi o seguinte:

em que

$$
\mathrm{Y}_{\mathrm{ijk}}=\mu+\mathrm{N}_{\mathrm{i}}+\mathrm{F}_{\mathrm{j}}+\mathrm{N}_{\mathrm{i}} \mathrm{F}_{\mathrm{j}}+\mathrm{E}_{\mathrm{ijk}}
$$

$\mathrm{Y}_{\mathrm{ijk}}=$ observação referente $\mathrm{a}_{\mathrm{i}}$ - éssima oferta, do ${ }_{\text {j- }}$ éssimo feno, na ${ }_{\mathrm{k} \text { - }}$ essima parcela;

$\mu \quad=$ média geral da variável;

$\mathrm{N}_{\mathrm{i}} \quad=$ efeito do ${ }_{\mathrm{i} \text { - }}$ éssimo nível de oferta, sendo $\mathrm{i}=30$ e $60 \%$;

$\mathrm{F}_{\mathrm{j}} \quad=$ efeito do $_{\mathrm{j}-}$ éssimo feno, sendo ${ }_{\mathrm{j}}=$ feno de rami, soja e capim-elefante napier;

$\mathrm{N}_{\mathrm{i}} \mathrm{F}_{\mathrm{j}}=$ efeito de interação entre o ${ }_{\mathrm{i}-}$ éssimo nível

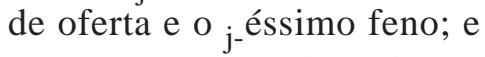

$\mathrm{E}_{\mathrm{ijk}}=$ erro aleatório associado a $\mathrm{Y}_{\mathrm{ijk}}$.

As médias de composição química dos fenos, das folhas e das hastes, consumo e ganho em peso foram comparadas pelo teste Tukey $(\mathrm{P}<0,05)$. As estimativas dos percentuais de PB, FDN, FDA e LIG selecionados pelas cabras foram comparados com os valores presentes nas rações e sobras pelo teste $t$ de Student $(\mathrm{P}<0,05)$, testando-se as hipóteses $\mathrm{H}_{\mathrm{o}}: \mathrm{m}=\mathrm{m}_{\mathrm{o}}$ e $\mathrm{Ha}: \mathrm{m} \neq \mathrm{m}_{\mathrm{o}}$ :

$$
\frac{\mathrm{t}=\overline{\mathrm{X}}-\mathrm{m}}{\mathrm{s}(\overline{\mathrm{X}})}
$$

em que
$\overline{\mathrm{X}}=$ estimativa da composição química da dietaingerida;

$\mathrm{m}=$ valor obtido para composição química das rações e sobras (considerado valor não-paramétrico); e $\mathrm{s}(\overline{\mathrm{X}})=\sqrt{ } \mathrm{QMR} / \mathrm{r}$ erro-padrão da média.

em que

$\mathrm{QMR}$ = quadrado médio residual da ANOVA; e

$\mathrm{r} \quad=$ número de observações para estimar $\overline{\mathrm{X}}$.

\section{Resultados e Discussão}

Qualidade dos fenos, da dieta ingerida e das sobras

Os resultados das análises de composição química dos fenos, das folhas e das hastes encontram-se na Tabela 1. O feno de rami apresentou maior teor de proteína $(\mathrm{P}<0,05)$ que os demais fenos. Os conteúdos da FDN e FDA dos fenos de rami e soja foram similares e inferiores $(\mathrm{P}<0,05)$ aos encontrados para o feno de capim-elefante var. napier. As folhas foram percentualmente mais ricas e apresentaram maior digestibilidade in vitro que os fenos e as hastes.

O feno de rami fornecido $60 \%$ acima do consumo do dia anterior estimulou a ingestão de porção mais rica em proteína e com menor teor de lignina $(\mathrm{P}<0,05)$ em relação à porção ingerida no nível de $30 \%$ (Tabela 2 ). $\mathrm{O}$ aumento da proporção de folhas na dieta ingerida com o crescimento da oferta explica as diferenças de

\begin{tabular}{|c|c|c|c|c|c|}
\hline \multirow[t]{2}{*}{$\begin{array}{l}\text { Composição } \\
\text { Composition }\end{array}$} & \multirow[t]{2}{*}{$\begin{array}{c}\text { Feno } \\
\text { Hay }\end{array}$} & \multicolumn{2}{|c|}{$\begin{array}{l}\text { Ingerido } \\
\text { Fed }\end{array}$} & \multicolumn{2}{|c|}{$\begin{array}{c}\text { Sobra } \\
\text { Orts }\end{array}$} \\
\hline & & $30 \%$ & $60 \%$ & $30 \%$ & $60 \%$ \\
\hline & Rami (Ramie) & & & & \\
\hline $\mathrm{PB}(C P), \%$ & $16,15^{\mathrm{c}}$ & $17,27^{b}$ & $18,65^{\mathrm{a}}$ & 12,97 & 12,72 \\
\hline FDN $(N D F), \%$ & $60,05^{\mathrm{a}}$ & $58,58^{\mathrm{ab}}$ & $56,08^{b}$ & 65,38 & 65,88 \\
\hline FDA $(A D F), \%$ & $48,20^{\mathrm{a}}$ & $45,49^{\mathrm{b}}$ & $43,59^{b}$ & 54,38 & 53,31 \\
\hline LIG (Lignin), $\%$ & $12,43^{\mathrm{a}}$ & $11,14^{\mathrm{b}}$ & $10,06^{\mathrm{c}}$ & 15,71 & 15,89 \\
\hline DIVMS (IVDDM), \% & 48,83 & - & - & 44,27 & 44,65 \\
\hline & Soja (Soybean) & & & & \\
\hline $\mathrm{PB}(C P), \%$ & $12,53^{\mathrm{b}}$ & $12,85^{\mathrm{a}}$ & $13,00^{\mathrm{a}}$ & 11,50 & 11,80 \\
\hline FDN $(N D F), \%$ & $64,85^{\mathrm{a}}$ & $63,89^{\mathrm{b}}$ & $63,91^{\mathrm{b}}$ & 67,89 & 63,70 \\
\hline FDA $(A D F), \%$ & $46,54^{\mathrm{a}}$ & $44,95^{\mathrm{b}}$ & $46,36^{\mathrm{ab}}$ & 50,61 & 47,14 \\
\hline LIG (Lignin), $\%$ & $9,06^{\mathrm{a}}$ & $7,48^{\mathrm{b}}$ & $6,40^{\mathrm{c}}$ & 13,87 & 13,26 \\
\hline DIVMS (IVDDM), \% & 56,19 & - & - & 48,60 & 51,00 \\
\hline & Napier (Napier gras & & & & \\
\hline $\mathrm{PB}(C P), \%$ & $4,52^{\mathrm{a}}$ & $4,25^{\mathrm{a}}$ & $4,31^{\mathrm{b}}$ & 4,63 & 4,78 \\
\hline FDN $(N D F), \%$ & $83,03^{\mathrm{a}}$ & $80,28^{a}$ & $83,64^{\mathrm{a}}$ & 83,69 & 82,40 \\
\hline FDA $(A D F), \%$ & $52,41^{\mathrm{a}}$ & $50,98^{\mathrm{b}}$ & $53,01^{\mathrm{a}}$ & 54,33 & 51,67 \\
\hline LIG (Lignin), $\%$ & $8,05^{\mathrm{a}}$ & $6,87^{b}$ & $7,63^{\mathrm{a}}$ & 9,82 & 8,54 \\
\hline DIVMS (IVDDM), \% & 43,96 & - & - & 41,23 & 45,94 \\
\hline
\end{tabular}
qualidade entre as porções ingeridas nos dois níveis de

a,b,c Médias, na linha, seguidas de diferentes letras são diferentes pelo teste Tukey $(P<0,05)$.

$a, b, c$ Means, within a row, followed by different letters are diferent by test Tukey $(P<.05)$. 
ofertas do feno de rami. Esta conclusão reforça o resultado de SHAND et al. (1987), que verificaram relação entre o aumento da oferta da palhada de cevada com a maior ingestão de folhas.

Com relação ao feno de soja, apenas o teor de lignina reduziu significativamente $(\mathrm{P}<0,05)$ com o aumento da oferta e, contrariando os resultados obtidos com o feno de rami, os teores de FDA e lignina ingeridos pelas cabras cresceram com o aumento da oferta do feno de capim-elefante napier.

Estes resultados podem ser atribuídos às diferenças na morfologia do material após a fragmentação. Embora a picadeira estivesse regulada para produzir partículas com tamanho médio de $0,4 \mathrm{~cm}$, o padrão de fragmentação não foi o mesmo entre os fenos. Enquanto o feno de rami apresentou folhas visualmente mais grosseiras que as hastes, o feno de capimelefante napier apresentou colmos e tecidos mortos.

Refletindo essa situação, a fração rejeitada do feno de rami, independente da oferta, apresentou valor nutritivo inferior ao do material originalmente oferecido às cabras (Tabela 2). Resultados menos expressivos foram observados com as sobras do feno de soja. As sobras do feno de capim-elefante napier raramente apresentaram os fragmentos mais grosseiros de tecidos senescentes e colmos presentes na porção oferecida. O material remanescente no cocho foi quase totalmente constituído por pequenos fragmentos de folhas, sugerindo consumo seletivo das piores partes do material oferecido, que explica o aumento do FDA e lignina na fração ingerida com o aumento da oferta e também torna complexa a compreensão do hábito seletivo dos caprinos.

O estímulo à escolha apenas com o aumento do nível de oferta de forragem (LOUCA et al., 1982) deve considerar as características de partículas produzidas após a picagem de diferentes espécies forrageiras.

Os resultados obtidos no presente ensaio mostraram que, ao se trabalhar com partículas de tamanho médio de $0,4 \mathrm{~cm}$, o aumento da oferta para induzir a escolha do alimento no cocho por caprinos se aplica melhor aos fenos de plantas de folhas largas como rami, em virtude da maior diferenciação morfológica entre folhas, hastes e caules em relação aos fenos de espécies de folhas estreitas como o capim-elefante napier. Isso foi evidenciado nos resultados obtidos por WAHED e OWEN (1986) e BROWN et al. (1987).

Estudos futuros devem considerar o efeito da fragmentação e estrutura foliar das espécies forrageiras sobre a qualidade do material ingerido por caprinos em regimes confinados.
A maior diferença percentual entre o conteúdo de proteína da porção ingerida e a oferecida ocorreu quando se utilizou o feno de rami, considerado volumoso de boa qualidade (Tabelas 1 e 2). Este resultado mostra que a eficiência do processo de escolha não depende, necessariamente, da baixa qualidade do volumoso, conforme sugeriram BROSH et al. (1987).

\section{Consumo de matéria seca}

O aumento da oferta do feno de rami (Tabela 3) estimulou o consumo das cabras $(\mathrm{P}<0,05)$. A maior ingestão de folhas no nível de oferta de $60 \%$ do feno de rami foi a principal explicação para esta resposta. Resultado semelhante foi obtido por MORANDFEHR (1981) com o aumento da oferta do feno de alfafa em 1,2, 3 e $4 \mathrm{~kg}$ de matéria seca.

Não houve efeito do nível de oferta sobre os consumos dos fenos de soja e capim-elefante napier.

Não existiram diferenças nas ingestões médias dos fenos de rami e soja, mas ambos apresentaram consumos superiores $(\mathrm{P}<0,05)$ aos do feno de capim-elefante napier, ao se considerarem cada nível de oferta em separado e médias (Tabela 3). Estes resultados foram atribuídos à falta de oportunidade de escolha do material e à baixa aceitabilidade do feno de capim-elefante napier por caprinos, em comparação com os outros fenos. A idade de corte avançada, cerca de 120 dias da rebrota, foi outro fator que contribuiu para os piores resultados com o capim-elefante napier.

Trabalhos anteriores confirmam que a idade do corte do capim-elefante napier compromete a sua aceitabilidade para caprinos. Segundo DEVENDRA e McLEROY (1982), na fase inicial de crescimento, o capim-elefante napier tem boa palatabilidade para caprinos, mas, com o amadurecimento das plantas, tanto a qualidade da forragem quanto o consumo caem abruptamente. Devendra (1974), citado por BROWN e JOHNSON (1984), obteve queda no consumo do capim-elefante napier de 88 para $61 \mathrm{~g} / \mathrm{kg} \mathrm{PV}^{0,75}$, quando os cortes foram realizados aos 30 e 60 dias, após a rebrota das plantas. De acordo com HARYANTHO et al. (1982), a preferência do capim-elefante napier por caprinos foi menor que a preferência por ramas de batata, mandioca e folhas de bananeiras.

\section{Ganho em peso}

Dentro de cada nível de oferta, as cabras alimentadas com feno de rami obtiveram maior ganho em peso $(\mathrm{P}<0,05)$ que as cabras alimentadas com feno de capim-elefante napier e feno de soja, respectivamente, no nível de 30 e $60 \%$ (Tabela 4).

Estudos futuros visando ao aproveitamento das 
Rev. bras. zootec.

Tabela 3 - Consumo de fenos em função da \% sobras diárias

Table 3 - Hays intake on the \% daily hays orts

\begin{tabular}{lccc}
\hline Feno & \multicolumn{2}{c}{$\begin{array}{c}\text { Consumo MS }(\% \mathrm{PV}) \\
\text { DM intake }(\% \mathrm{LW})\end{array}$} & $\begin{array}{c}\text { Média de feno } \\
\text { Hay average }\end{array}$ \\
\cline { 2 - 3 } & $30 \%$ & $60 \%$ & \\
\hline Rami & $1,0^{\mathrm{bAB}}$ & $1,5^{\mathrm{aA}}$ & 1,2 \\
$\begin{array}{l}\text { Ramie } \\
\text { Soja }\end{array}$ & $1,2^{\mathrm{A}}$ & $0,9^{\mathrm{B}}$ & 1,1 \\
$\begin{array}{l}\text { Soybean } \\
\text { Napier }\end{array}$ & $0,5^{\mathrm{B}}$ & $0,5^{\mathrm{B}}$ & 0,5 \\
$\begin{array}{l}\text { Médias } \\
\text { de níveis }\end{array}$ & 0,9 & 1,0 & \\
Average levels & & & \\
\hline CV $(\%)$ & 36,05 & \\
\hline
\end{tabular}

Médias, na linha/coluna, seguidas de letras maiúsculas/minúsculas diferentes são diferentes pelo teste Tukey $(P<0,05)$.

Means, within a row/column, followed by different small/capital letters are different by Tukey test $(P<.05)$

sobras, em função de sua quantidade e qualidade, de uma espécie animal mais seletiva para uma menos seletiva, é importante para a continuidade desta linha de pesquisa.

\section{Conclusões}

O aumento da oferta do feno de rami melhorou o valor nutritivo da dieta ingerida e o consumo de matéria seca, em função da maior ingestão seletiva de folhas.

O ganho em peso dos caprinos alimentados com feno de rami foi superior ao de animais alimentados com feno de capim-elefante napier. Estes resultados sugerem que o feno de rami é mais adequado para uso na alimentação de cabras com excesso de oferta.

\section{Referências Bibliográficas}

BROWN, D.L., WEIR, W.C. Increasing efficiency of goat production available resources and strategies problems, challenges, and required nutrition base. In: INTERNATIONAL CONFERENCE ON GOATS, 4, 1987, Brasília. Proceedings... Brasília: EMBRAPA, v.1, 1987. p.43-53.

BROSH, A., SHKOLNIK, A., CHOSHNIAK, I. 1987. Effects of infrequent drinking on the nitrogen metabolism of Bedouin goats maintained on different diets. J. Agric. Sci., 109:165-169.

BROWN, D., SALIM, M., CHAVAliMU, E., FITZHUGH, H. 1988. Intake, selection, apparent digestibility and chemical composition of Pennisetum purpureum and Cajanus cajan foliage as utilized by lactating goats. Small Rumin. Res., 1:59-65.

BROWN, L.E., JOHNSON, W.L., 1984. Comparative intake and digestibility of forages and by products by goats and sheep: A review. International Goat and Sheep Reseach, 2: 212-226.

DEVENDRA, C., McLEROY, G.B. 1982. Feeds and feeding. In: Goat and sheep production in the tropics. Nova Iorque: Longman, Parte. 1, p.55-72.

HARYANTHO, R., JOHNSON, W.L. THOMAS, N. Intake
Tabela 4 - Ganho em peso (GP) em função da \% sobra diária

Table 4 - Weight gain (WG) on the \% daily hays orts

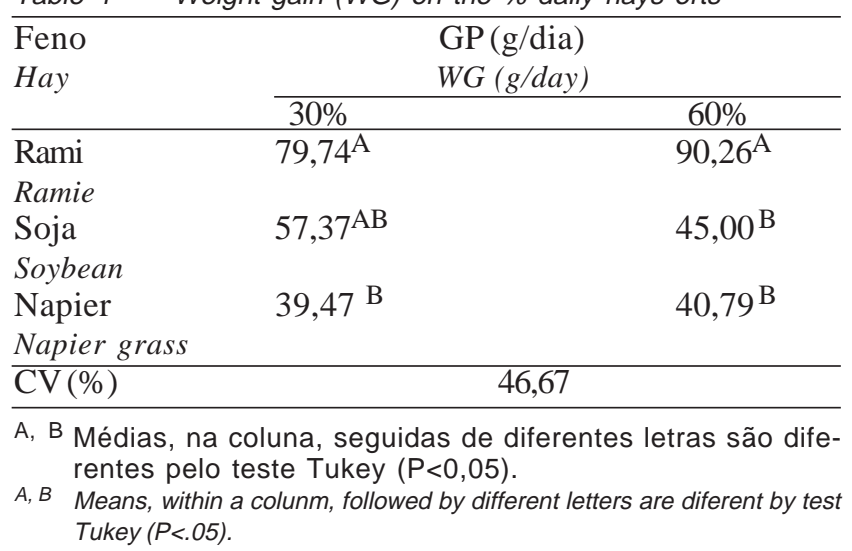

preferences for cassava, sweet potato, banana and napier grass foliages by indonesian sheep and goats. In: INTERNATIONAL CONFERENCE ON GOAT PRODUCTION AND DISEASE, 3, Tuckson, 1982. Proceedings... Tuckson: 1982. p.279.

JOHNSON, W.L., VAN EYS, J.E. Recent concepts in tropical forage utilization by oats. In: INTERNATIONAL CONFERENCE ON GOATS, 4, Brasília, 1987, Proceedings... Brasília: EMBRAPA, 1987, v.2, 1063-1076.

LOUCA, A., ANTONIOU, T., HATZIPANAYIOTOU, M. Comparative digestibility of feedstuffs by various ruminants, epecifically goats. In: INTERNATIONAL CONFERENCE ON GOAT PRODUCTION AND DISEASE, 3, Tuckson, 1982, Proceedings... Tucson: 1982. p.122-32.

MORAND-FEHR, P. 1981. Nutrition and feeding of goats: Application to temperate climaticcondictions. In: GALL, C. Goat Production. London: Academic Press, Cap. 6, p.193-232.

NATIONAL RESEARCH COUNCIL - NRC. 1981. Nutrient requirements of goats. Washington: National Academy Press. 91p.

OWEN, E.A, WAHED, R.A, ALIMON, R. Effect of amount offered on selection and intake of barley straw by goats. In: INTERNATIONAL CONFERENCE ON GOATS, 4, Brasília, 1987. Proceedings... Brasília, EMBRAPA: 1987. 2:1376.

SHAND, W., SHERATA, O., ORSKOV, E.R. 1987. Studies on botanical proportions and nutritive value of varieties of cereal straws and the ability of sheep to select the botanical part with the greatest value. Anim. Prod., 44:480.

SILVA, D.J. 1990. Análise de alimentos: métodos químicos e biológicos. Viçosa, MG: UFV, Imp. Univ. 165p.

UNIVERSIDADE FEDERAL DE VIÇOSA. SAEG. 1982. Sistema de análises estatísticas e genéticas. Viçosa: Universidade Federal de Viçosa, Manual do usuário, 150p.

WAHED, R.A., OWEN, E. 1986. Comparison of sheep and goats. Under stall-feeding condictions: Roughage intake and selection. Anim. Prod., 42:89-95.

Recebido em: 28/07/98

Aceito em: 12/04/99 